\title{
Die sosiale en gemeenskapsdinamika van projekbestuur
}

\author{
C.Brown \\ Nagraadse Bestuurskool, Universiteit van Stellenbosch, Posbus 610, Bellville, 7535 Republiek van Suid-Afrika
}

Ontvang Augustus 1995

\begin{abstract}
The need for the study originated mainly from the political reforms in South Africa, which have incited public insistence on community involvement in the planning, decision-making and execution of projects which people perceive are of concern in their everyday lives. Many project managers in South Africa are faced with hitherto unknown social forces and elements in the execution of their missions, which they are often not adequately trained for. The purpose of the study is to extend the 'conventional' project management processes to include community participation, because in the past, the social $\operatorname{system}(s)$ within which projects are situated and the social dynamics inevitably evoked by the implementation thereof, were too often ignored. The article considers an appropriate meaning of community participation, which inter alia means that the community be enabled to influence the direction and outcome of projects. That implies that managerial decisions will in future have to involve social besides economic choices. The overriding importance of the search for common interests is emphasized. A model for involving the community in project-concept forming is presented. The article concludes with a basic truth, namely that there are many projects which will simply not succeed without full consultation with the community from the earliest possible stage.
\end{abstract}

Die behoefte vir hierdie studie het ontstaan uit die politieke hervorming in Suid-Afrika wat openbare aandrang op gemeenskapsbetrokkenheid in die beplanning, besluitneming en uitvoering van daardie projekte wat mense dink hulle daaglikse lewens sal raak, aangevuur het. Gevolglik word baie projekbestuurders in die uitvoering van hulle missies nou gekonfronteer met sosiale kragte en elemente wat tot dusver vir hulle onbekend was en waarvoor hulle waarskynlik nie behoorlik opgelei is nie. Die doelwit van die studie is om die 'konvensionele' projekbestuursprosesse uit te brei om gemeenskapsdeelname in te sluit, omdat die sosiale stelsel(s) en dinamika waarin die projekte gesetel is, in die verlede te dikwels geïgnoreer is. Die artikel behandel die ware betekenis van gemeenskapsdeelname wat onder andere beteken dat die gemeenskap in staat gestel moet word om die rigting en resultate van projekte te beinvloed. Dit impliseer dat bestuursbesluite voortaan ook op sosiale benewens ekonomiese keuses gebaseer moet wees. Die soeke na gemeenskaplike belange word beklemtoon. ' $n$ Model vir die betrekking van die gemeenskap in die formulering van die projekkonsep word aangebied. Die artikel sluit af met 'n kontemporêre basiese waarheid, naamlik dat baie projekte eenvoudig nie sal slaag sonder volledige konsultasie met die gemeenskap vanaf die vroegste oomblik nie.

\section{Inleiding}

Die behoefte vir hierdie studie ontstaan primêr uit die vanselfsprekende, maar noodsaaklike rol van projekbestuur in die Heropbou en Ontwikkelingsprogram (H.O.P.) vir SuidAfrika. In die verlede was die meerderheid van die bevolking hoofsaaklik betrokke by vraagstukke wat die breë Suid-Afrikaanse gemeenskap geraak het, byvoorbeeld apartheid. Die onlangse transformasie in die makro-politieke omgewing, die sosio-ekonomiese veranderinge veroorsaak deur, sowel as die algemene doelwitte van die H.O.P., het egter 'n klemverskuiwing veroorsaak waardeur gemeenskapsleiers en die algemene publiek skerp op sosiale vraagstukke binne hulle eie (mikro)gemeenskappe gefokus geraak het. Vir ingenieurs en projekbestuurders lei dit in die uitvoering van hulle missies tot toenemende konfrontasie met sosiale kragte en elemente wat tot dusver hoofsaaklik onbekend vir hulle was, waarvoor hulle nie opgelei is nie en waartoe 'n dringende heroriënteringsbehoefte ontstaan het. Hierdie sosiale kragte ontstaan hoofsaaklik uit die demokratiseringsprosesse en manifesteer in openbare aandrang op gemeenskapsbetrokkenheid in die beplanning, besluitneming en uitvoering van daardie projekte wat mense dink hulle daaglikse lewens sal raak.

Die doelwit van die studie is om die tekortkominge in die 'konvensionele' projekbestuursprosesse aan te spreek, wat skynbaar ontstaan het weens die verontagsaming van die sosiale kragte en die sosiale stelsel(s) waarin projekte geïmplementeer moet word. Karige aandag is in die verlede aan die breë sosiale faktore van projekbestuur en aan die betrokkenheid van die bevoordeeldes in projekbeplanning en projekimplementering deur projekbestuurskursusse, hand- boeke en studiemateriaal bestee (Bamberger, 1988: 19). Selfs die PMBOK' is hieraan skuldig. Ervaring oor 'n wye front in Suid-Afrika sowel as literatuur oor ervaring elders het egter bevestig dat juis die ignorering van hierdie 'sosiale dinamika' 'n belangrike faktor in die mislukking van projekte in SuidAfrika is. Hoewel dit tans eintlik net waar is van openbare sektorprojekte wat dienste aan onderontwikkelde gemeenskappe moet lewer, is dit ook vinnig besig om van die uiterste belang vir die privaatsektor te word, omdat privaatsektor projekte voortaan na alle gemeenskappe geneem sal moet word en nie slegs in 'gerieflike' gebiede geplaas kan word nie.

\section{Wat beteken sosiale en gemeenskapsdinamika in die konteks van projekbestuur?}

In die eerste plek is die basiese vertrekpunt van hierdie studie 'n stelselsbenadering waarin die projek beskou word as ' $n$ element, en wat dus ' $n$ interaksie het met al die ander elemente van die sosiale stelsel van die betrokke gemeenskap waarin of waarvoor die projek beoog word. Vir 'n nominale voorstelling van die elemente van so 'n stelsel, kyk na Bylae A. Dit is die 'sagte' benadering, in teenstelling met die 'harde' benadering wat konvensioneel deur ingenieurs gevolg word, soos in Figuur 1 geïllustreer word.

In die tweede plek word aksiomaties aanvaar dat enige projek wat in 'n gemeenskap geimplementeer gaan word, emosies van een-of-ander aard sal ontketen wat sal lei tot dinamiese sosiale interaksie binne die teikengemeenskap, asook met die projekspan. Die projekbestuursprosesse en projekbestuurstrukture sal hierdie gemeenskapsdinamika moet ondervang, verstaan en korrek reflekteer. 


\begin{tabular}{|l|l|l|}
\hline $\begin{array}{l}\text { Harde stelsels } \\
\text { Hoe, waarmee, wan- } \\
\text { neer - dit is doel- } \\
\text { witte en beheer } \\
\text { Meganika }\end{array}$ & $\rightarrow$ Projekuitvoering & $\begin{array}{l}\text { Sagte stelsels } \\
\text { Waarom, wat, wie } \\
- \text { dit is waardes en } \\
\text { betrokkenheid } \\
\text { Dinamika }\end{array}$ \\
\hline
\end{tabular}

Bron: skrywer se eie verwerking

Figuur 1 Harde en sagte stelsels van projekbestuur

In die derde plek impliseer die voorafgaande besprekings dat ' $n$ gemeenskapsoriëntering van die bestuur van die projek fundamenteel is tot die suksesvolle implementering daarvan. Dit lei tot die begrip 'gemeenskapsdeelname aan projekbestuur' wat gebaseer word op 'n program van interaksie en aktiewe kommunikasie en raadpleging tussen die projekspan en die geaffekteerde gemeenskap, waaroor later uitgebrei sal word.

Vierdens moet in die geval van Openbare sektorprojekte onderskei word tussen die voordeeltrekkers van die projek (wat die voordele ontvang maar vir weinig koste aanspreeklik is) en die projekpromotor (wat nie die direkte voordele ontvang nie, maar die projek help inisieer en vir die meerderheid koste verantwoordelikheid aanvaar). Die eersgenoemde kan beskou word as die 'kliënt(e) vir die produk' en die laasgenoemde as die 'kliënt vir die projek'. Hierdie onderskeid is noodsaaklik omdat ' $n$ 'twee-kliëntebenadering' impliseer dat konsensus tussen die kliënte aangaande die projek van primêre belang is. Ook dat die partye wat by die projek betrokke is, gedurende die hele lewensiklus daarvan gewikkel is in 'n soeke na die balans tussen aktiewe beïnvloeding van die rigting en resultate van die projek deur die eersgenoemde 'kliënt' en realistiese besluitneming ten opsigte van die fiskale en fisiese beperkings deur die laasgenoemde.

Vyfdens het sosiale dinamika hoofsaaklik betrekking op kommunikasieprosesse. Kommunikasie is voor-die-hand-liggend nodig vir die fasilitering van die deelname van die gemeenskap aan die formulering van die projekomvang, sowel as die ontwikkeling van die prosesse en strukture om sodanige deelname te verkry. Vir effektiewe kommunikasie moet voorsiening gemaak word vir die identifisering van die 'ware' gemeenskapsleiers, die organisering van die gemeenskap in verteenwoordigende en onderhandelingstrukture en gereelde terugvoering aan die gemeenskap om sodoende aanvaarding (soms 'eienaarskap') van die projek in hulle omgewing te verhoog.

Daar word gereeld deur die media berig oor weerstand teen, of ontevredenheid van inwoners oor spesifieke of voorgestelde projekte wat hulle dink hulle gemeenskap sal raak. In 'n onlangse opname onder senior amptenare van plaaslike owerhede in die Weskaap Provinsie met betrekking tot die oorsake van sulke ontevredenheid, het die respondente gereageer soos in Tabel 1 aangetoon.

Daar is dus klaarblyklik voldoende konsensus oor die fundamentele belang van kommunikering met die gemeenskap by die uitvoering van projekte as ' $n$ voorvereiste om suksesvol te wees.

In die laaste instansie bied sinvolle interaksie met die gemeenskap die voordeel van die benutting van die kennis van

\begin{tabular}{llll}
\hline Tabel 1 Oorsake van ontevredenheid met projekte \\
\hline $\begin{array}{l}\text { Oorsaak van ontevredenheid } \\
\text { stem }\end{array}$ & $\begin{array}{l}\text { Snseker Stem ne } \\
\text { saam nie }\end{array}$ \\
\hline $\begin{array}{l}\text { Noodsaaklikheid van projek word nie effektief aan } \\
\text { gemeenskap gekommunikeer nie }\end{array}$ & $78 \%$ & $9 \%$ & $13 \%$ \\
$\begin{array}{l}\text { Gebrek aan vestiging van projekeienaarskap by die } \\
\text { gemeenskap }\end{array}$ & $88 \%$ & $7 \%$ & $5 \%$ \\
$\begin{array}{l}\text { Nie-effektiewe terug voer oor projekvordering na } \\
\text { gemeenskap }\end{array}$ & $77 \%$ & $15 \%$ & $8 \%$ \\
$\begin{array}{l}\text { Gemeenskap se behoefte aan terugvoer nie ge- } \\
\text { identifiseer nie }\end{array}$ & $71 \%$ & $24 \%$ & $5 \%$ \\
$\begin{array}{l}\text { Onvoldoende onderhandeling oor gemeenskap se } \\
\text { verwagtinge met betrekking tot realistiese } \\
\text { besluitneming }\end{array}$ & & & \\
\hline \begin{tabular}{l} 
Bron: Brown (1994:6) \\
\hline
\end{tabular} & $75 \%$ & $20 \%$ & $5 \%$ \\
\hline
\end{tabular}

plaaslike omstandighede oftewel 'inheemse tegniese kennis', wat soos volg deur Chambers omskryf word:

'Indigenous technical knowledge (ITK) is now respected more, and valued not only for its validity and usefulness, but because it is part of the power of the poor. ITK is strong on knowledge of local diversity and complexity, precisely where outsiders' knowledge is weak. In rapid change, its advantages over outsiders' knowledge are even greater' (1993: 11).

\section{Omskrywing van gemeenskapsdeelname}

Daar bestaan verskeie standpunte oor wat gemeenskapsdeelname behels. Volgens Paul (1987: 2) word die term soms gebruik om aktiewe deelname aan politieke besluitneming te beteken; die aktivistiese standpunt is dat die publiek ('the people') betekenisvolle beheer oor die produkleweringsproses moet hê; en ontwikkelingsekonome neig om deelname te definieer in terme van billike verdeling van die voordele van projekte. Verder, om 'n definisie van werklike deelname deur gemeenskappe aan die bestuur van projekte te kan formuleer, moet gemeenskapsdeelname, volgens Bamberger (1988: 5), nie met gemeenskapsontwikkeling verwar word nie. Die laasgenoemde, wat 'n populêre konsep in die 1960's was, word nou beskou as om 'n kolonialistiese en neerbuigende betekenis te hê (Bamberger, 1988: 5). Dit geld ook vir die terme 'sosiologiese en/of ekonomiese opheffing' (Mokgoro, 1993). Die rede vir gemeenskapsdeelname behoort dus nie te wees om mense 'op te hef' nie, maar om die publiek ' $n$ deelname te gee aan besluitvorming oor sake wat die potensiaal het om hulle lewens te beinvloed, soos gestel in Cuta (1990: 9) 'opening up greater access to the decision making process to all people'. Met inagneming van die bogenoemde bespreking word die definisie van Paul, effens aangepas vir die doeleindes van hierdie referaat, derhalwe as die korrekte voorgehou:

'Gemeenskapsdeelname aan projekbestuur is die aktiewe proses waardeur bevoordeelde/kliëntgroepe die rigting en uitvoering van 'n projek beïnvloed, eerder as om slegs gekonsulteer te word of om net ' $n$ deel van die projekvoordele te verkry' (1987: 5).

Hierdie definisie hou 'n aantal belangrike oorwegings vir die projekbestuursproses in. 
Eerstens is die konteks vir die deelname die definiëring van die doelwitte en produkte van die projekte en nie die beheer oor die projekbestuur as sodanig nie. Gemeenskapsdeelname kan baie maklik lei tot prysgawe van die beheer oor die projekbestuursproses aan die publiek, wat Bamberger (1988: 11) onwrikbaar glo nooit moet gebeur nie, nieteenstaande die beste bedoelinge met deelnemende aksies. Die breë publiek beskik nóg oor die opleiding nóg oor die insig om die tegniese en bestuursbesluite te kan neem wat nodig is om ' $n$ gladde uitvoering van die proses te verseker. Dit impliseer ook 'n afsnypunt waar die deelnemende aksies van die publiek oorgaan in bestuur deur die projekspan, soos aangetoon in Bylae B.

Tweedens is die fokus op die deelname van die geaffekteerde gemeenskap en nie op die van die projekpromotor of projekdonateur(s) nie. Wat van primêre belang is, is die aanvaarding van die projek of die produkte daarvan in die sosiale stelsel waarin dit geleë sal wees, want dit is wat die implementering en uiteindelike sukses van die projek sal bepaal.

Derdens word openbare deelname gekenmerk deur gesamentlike optrede deurdat die gemeenskap as 'n groep adviseer, besluit of optree met betrekking tot vraagstukke. Die implikasie hiervan vir die bestuur van 'n projek is dat die organisering van die gemeenskap om eendragtig op te tree, ook dikwels op die skouers van die projekbestuurder val.

In die vierde plek behels gemeenskapsdeelname 'n vennootskap tussen gelyke vennote vir die oplossing van probleme rondom die projek, wat soos volg beskryf kan word:

'Participation means partnership, connecting horizontally amongst people of equal status (not necessarily equal power) and vertically between those who set policies and those who live within the framework of those policies. And partnership means not only that one shares in the action of others, but is involved with others, developing options, negotiating priorities and agreeing on directions' (Goethert \& Hamdi, 1988: 24).

Gemeenskapsdeelname aan projekbestuur is egter 'n uiters komplekse saak, waar die klem op die proses (van deelname deur die bevoordeeldes) eerder as op die produk behoort te val, wat soos volg deur Goethert \& Hamdi beskryf word:

'It is characterized by innumerable groups of people with competing vested interests, conflicting values and priorities, and by fragile yet productive networks and relationships, high densities, petty economies and technically difficult-to-service neighbourhoods. Statistical information is hard to get, and even when it is not, it often hides as much as it reveals. Governments want quick visible results which can rapidly expand the scale of their operation, but find themselves encumbered with processes and conditions which do not fit their general schema nor any general theory of planning and with which they are ill equipped to deal. What they confront are processes which are spontaneous, intuitive, incremental, mostly unregulated and with a large measure of adhocism.

And what they also confront are people who like "planning" because it gives them more than they had before, but mistrust it because they always get less than they expect' (1988: 16).
Dit is juis hierdie klem op die proses, wat meestal tydsaam, frustrerend en herhalend kan wees en noodwendig demokra. ties is, wat volgens Bamberger (1988: 6) die grootste uitdaging aan die doelgerigtheid en enkelpuntverantwoordelikheid van die ervare konvensionele projekbestuurder bied.

In die geval van openbare sektorprojekte het die proses ten doel om die waardes van die owerhede en dié van die geaffekteerde gemeenskap(pe) uiteindelik te versoen. In die geval van privaatsektorprojekte het die proses ten doel om potensiële negatiewe uitwerking te identifiseer en te vermy of tot aanvaarbare vlakke te verminder, óf potensiële positiewe uitwerking te versterk. Die proses van projekformulering en projekbeplanning waarby geaffekteerde gemeenskappe insette lewer, behoort dus net so belangrik as die implementering beskou te word. Tensy hierdie (omvattende) proses deursigtig, geloofwaardig en vir die publiek aanvaarbaar is, sal weinig projekte deurgevoer kan word (Cuta, 1990: 2).

\section{Doelwitte van gemeenskapsdeelname}

Vir openbare sektorprojekte (dit is infrastruktuur, openbare voordeel of nie-winsgewend) behoort projekbestuur na die volgende doelwitte ten opsigte van openbare deelname te streef:

\section{Om projekkoste te deel}

Deur betekenisvolle bydraes met betrekking tot die rigting en resultate van 'n projek met 'n gemeenskap te onderhandel en daardeur 'eienaarskap' van die projek en waarvan hulle uiteindelik die bevoordeeldes gaan wees, in dié mense te vestig, kan legitieme verantwoordelikheid vir die verhaling van minstens ' $n$ deel van die koste verwag (en beding) word. Talle voorbeelde bestaan in Suid-Afrika waar, na die spandering van kapitaal, die mense weier om vir die dienste te betaal omdat hulle na bewering nie geraadpleeg is of 'eienaarskap' verkry het nie. Dié verantwoordelikheid kan uitgeoefen word nie net deur huur- en diensgelde nie maar deur bydraes in die vorm van arbeid, onderhoud en selfs gereedskap. Dit sal ook die funksie van gemeenskapsdeelname wees om begrip vir die koste-elemente en aanspreeklikheid vir 'n regverdige gedeelte daarvan oor te dra.

\section{Verhoging van projekdoeltreffendheid}

Met tydige insette kan koste aanmerklik verminder word deur die vermindering van vertragings, diefstal en vandalisme, deur ' $n$ gladder verloop van sake en 'n algemene klimaat van samewerking en derhalwe ook verhoogde vlakke van toesig wat produktiwiteit dramaties verhoog (Siviele Ingenieurswese, 1993: 9). Gewoonlik kan die inwoners se kennis van plaaslike omstandighede ook voordelig benut word, wat die reeds genoemde standpunt van Goethert \& Hamdi (die 'ITK') bevestig.

\section{Verhoging van projekeffektiwiteit}

Met 'n effektiewe projek word doelwitte bereik in ooreenstemming met 'n gemeenskap se behoeftes en beperkings en waar die voordele verkry word deur dié vir wie dit beoog is. Volgens Cuta (1990: 26) kan dit verkry word deur' $n$ proses om die owerheid se begrip vir en empatie met die publiek se opinie te verseker; om die publiek se hulp met die identifisering van alternatiewe en die selektering van 
alternatiewe optredes te verkry; en om die publiek se begrip vir owerheidsprogramme en die implikasies van potensiële alternatiewe te verseker.

\section{Bou die bevoordeelde se vermoēns ('capacity building')}

Hierdie doelwit beteken dat die bevoordeeldes nie net fisiese produkte kry nie, maar dat hulle deur aktief betrokke te wees in projekbeplanning en -implementering ook verskillende vaardighede op die een of ander manier verwerf. Stewart (1993: 22) is van mening dat dit 'n noodsaaklike doelwit reg van die begin af moet wees omdat hy gevind het dat die vermoë van die gemeenskap om deel te neem, nieteenstaande die projekpromotor se gewilligheid om hulle te betrek, dikwels beperk word deur 'n gebrek aan kennis en 'n gebrekkige vermoë om redelike oordeel oor hulle eie deelname te maak. Goethert \& Hamdi (1988: 18) het bevind dat 'n gebrekkige vermoë om die probleem behoorlik te kan omskryf ('articulation of the problem') en om 'n gepaste raamwerk te kan formuleer waarteen alternatiewes opgeweeg kan word, dic vermoë om deel te neem ernstig benadeel. Landelike gemeenskappe is in die opsig gewoonlik nog slegter daaraan toe.

Een manier om vaardighede te ontwikkel, is deur ' $n$ bestuurde konstruksieprogram ('managed construction-programme') met die aanwending van 'gemeenskapskontrakteurs'. Dit beteken dat individue uit die gemeenskap toegelaat word om klein gedeeltes van die werk met behulp van ander persone (ook uit die gemeenskap) uit te voer, as entrepreneurs in plaas van direk geëmplojeerde arbeid (Siviele Ingenieurswese, 1993: 8). Verder kan die ontwikkeling van vaardighede ook verkry word deur formele leierskapsontwikkelingsprogramme, leer deur self te doen, die bewustheid van 'bemagtiging deur vaardigheid' te verhoog, of die gebruik van nabootsingsprogramme waardeur persone (en gemeenskappe) leer om hulle eie behoeftes te verstaan en alternatiewe oplossings te identifiseer. Dit impliseer dat elemente van mentorskap en opleiding in die projekuitvoering en in die kontrakadministrasie voorsien moet word, wat duidelik 'n nuwe, belangrike dimensie by die taak van die projekbestuurder voeg.

\section{Bemagtiging}

Bemagtiging van mense beteken dat hulle die vermoë verwerf (of ontwikkel) om self oor hulle toekomstige aksies te besluit. Hiertoe is gemeenskapsdeelname ongetwyfeld ' $n$ instrument. Die implikasie hiervan is egter dat die projekbestuurder nie meer die uitvoering van 'n projek in 'n gebied (of gemeenskap) volgens ' $n$ voorafbeslote plan op 'n bo-na-onder wyse kan aanpak nie. Konsultasie, kommunikasie en deelname deur die publiek ten einde hulle in staat te stel (te bemagtig) om betekenisvolle beheer te kan uitoefen oor die uiteinde van die projek, sal derhalwe vereistes van die projekbestuursprosesse wees.

Melding is reeds gemaak dat privaatsektorprojekte toenemend in agtergeblewe gebiede gevestig sal word, byvoorbeeld winkelsentrums, kantore, skoon nywerhede, ensovoorts. Die betrokkenheid van die gemeenskappe in die omgewing van sulke projekte kan (sal?) ongetwyfeld die suksesvolle bestuur daarvan beïnvloed. In daardie gevalle is koste en bemagtiging nie oorwegings nie; wel projekeffektiwiteit en -doeltreffend- heid. Die aantal projekte in Suid-Afrika waar hierdie konsep geïgnoreer is tot die nadeel van skedules, koste en effektiwiteit van die projekte, neem steeds toe. Voorbeelde sluit in die Houtbaai Kaolien-mynprojek (kwaai weerstand van omgewingsbewustes wat na bewering nie geraadpleeg is nie); die 'Namaqua Sands'-projek (bewerings deur die boeregemeenskap dat die projek die [alreeds] swak infrastruktuur beskadig, en dat beloftes in dié verband deur die projekpromotor nie nagekom is nie); die 'St Lucia Dunes'-mynprojek (lang uitgerekte toutrekkery met die omgewingsbewustes).

\section{Impak van sosiale en gemeenskapsdinamika op projekbestuur}

1. Die bestuur van projekte omvat nie net die bereiking van tegniese doelwitte binne fiskale beperkings nie, maar sal ook die 'bestuur' van die sosiale stelsel moet behels, wat die volgende moet insluit:

- identifisering van die elemente van die sosiale stelsel van die omgewing waarin die projek geplaas moet word, sowel as die identifisering van die kritieke verwantskappe tussen die elemente (kyk Bylae A); en

- organisering van gemeenskapstrukture wat hierdie elemente en verwantskappe sal ondersteun, met die bedoeling om konsultasie, kommunikasie en konsensus met die gemeenskap te bevorder. As eerste kontak kan ekonomiese en ontwikkelingsforums benut word. Hieruit word spesifieke projekforums saamgestel, bygestaan deur werks- of moniteringskomitees wat met mindere of meerdere mate van sukses al beproef is. Die rol en posisie van die projekbestuurder in hierdie komitees, veral ten opsigte van die behoud van die bestuur en beheer van die projekspan moet baie deeglik, tydig uitgepluis word. Ervaring het geleer dat aansienlike heroriëntering van projekbestuurders en baie dikwels van burokrate, deur middel van opleiding nodig is om met plaaslike groepe te skakel en saam te werk eerder as om hulle as ' $n$ bedreiging te beskou.

2. Soos verwag kan word vanuit die 'politiek van die dag' is die sosiale dinamika binne gemeenskappe sterk ingestel op die verkryging van 'n (meer) regverdige samelewing. By implikasie sal dit met 'n sigbare ekonomiese en welvaartsverdeling gepaard moet gaan. Om dit op 'n volgehoue basis te verkry, kan met die bestuur van projekte 'n bydrae gelewer word deur projekte te gebruik vir:

- die skepping van entrepreneurskap en begrip vir besigheids- en vrye markbeginsels;

- opleiding in tegniese en bestuursvaardighede;

- mentorskap van gemeenskapskontrakteurs; en

- toepaslike tegnologie aan te wend wat voorsiening maak vir verhoogde hande-arbeid.

3. Enige projek sal weens die feit dat dit bedoel is om 'n verandering te weeg te bring, sosiale dinamika van die eenof-ander aard binne die betrokke sosiale stelsel ontketen. Die projekspan is dus daarop aangewese om koalisies binne die gemeenskap op te bou om hierdie dinamiese sosiale interaksie positief te beinvloed en tot suksesvolle bestuur van die projekte aan te wend (Goethert \& Hamdi, 1988: 5\&7).

4. Die projek, die politiek wat onlosmaaklik verweef is met die verwagtinge van die gemeenskap, en die moontlike 
ekonomiese gevolge van die projek is inderdaad almal elemente van die plaaslike sosiale stelsel. Uit die aard van 'n stelsel, waar geen element onafhanklik kan optree nie, sal bestuursbesluite dikwels politieke keuses sowel as ekonomiese/tegniese keuses in ag moet neem. Meer as 'n werkbare kennis van die 'politiek van die dag' in die teikengebied is dus noodsaaklik (Mokgoro, 1993).

5 Die projekspan moet aanvaar dat die bevoordeeldes/geaffekteerde gemeenskap die rigting en resultaat van die projek sal beïnvloed. Dit sal in die meeste gevalle 'n grondige impak op die prosesse vir die formulering van die projekomvang en op die konsepfase van die projeklewenssiklus hê. Verskeie siklusse van 'n verkenning- of konsepidentifiseringsproses word gewoonlik benodig. In hierdie fase sal onderhandelings--, bemarkings-, openbare betrekkinge- en innovasievaardighede, sowel as begrip van die dinamika in die teikengemeenskap, tot die uiterste beproef word (kyk Bylae C).

Verder beveel Cuta (1988: 31) aan dat, gebaseer op ondervinding, openbare betrokkenheid so gou moontlik verkry moet word en dwarsdeur die beplanningsfase behou moet word, en verder, 'It is extremely difficult to commence discussions (with the community) when projects are under way and certain parameters have already been fixed'. Wat die situasie nog meer ingewikkeld maak, is dat die projekspan dikwels eers die gemeenskap moet organiseer en verteenwoordigende strukture moet skep (Mokgoro, 1993); Stewart, (1993: 22).

6. 'n Bo-na-onder benadering tot gemeenskapsdeelname en formulering van die projek se omvang is nie uitvoerbaar nie. Dit moet vervang word met 'n 'middel-uit'-benadering waar die projekbestuurder en die gemeenskap vennote word in die soektog na wedersyds voordelige oplossings.

7. Volg 'n stadig-vinnige benadering in plaas van 'n vinnigstadige benadering.

In die vinnig-stadige benadering, is projekformulering hoofsaaklik 'n tegniese oefening, voorberei deur die projekpromotor se professionele span. Betrekking van die publiek is slegs 'n plig sover dit wetlik vereis word. Wanneer planne dan geopenbaar word, word gewoonlik sterk weerstand ondervind wat die doelwitte van die promotor bedreig. Die tyd spandeer aan konsepformulering is 'n minimum, maar tyd spandeer aan ontwikkeling en uitvoering, asook vir projek- en plangoedkeuring kan baie uitgerek raak omdat mense negatief reageer wanneer hulle 'n persepsie het dat al die belangrike besluite alreeds geneem is. Openbare weerstand en skeptisisme is die gevolg.

In die stadig-vinnige benadering word openbare betrokkenheid van die eerste oomblik af nagestreef en dit word volgehou vanaf goedkeuring deur implementering tot monitering. Konsepformulering en planvoorbereiding is stadig, terwyl ontwikkeling, goedkeurings en implementering vinnig verloop orndat die mense vol vertroue is dat die projekplan sake sal aanspreek en oplos wat vir hulle betekenisvol is.

\section{Strukture vir die hantering van gemeenskapsdina mika}

Uit die voorafgaande is dit duidelik dat gestreef moet word na fasilitering van projekimplementering saam met die gemeenskap en nie vir die gemeenskap nie. Ten einde struktuur hieraan te verleen, maak Stewart (1993: 22-26) die volgende aanbevelings:

1. Maak die vroegste moontlike kontak met die gemeenskap om so gou moontlik bewustheid en begrip vir die rede vir die projek en die voordele daarvan te probeer vestig.

2. Bied daarom allereers die basiese beweegredes en uitgangspunte ten opsigte van die projek aan al die mense op 'n openbare vergadering. Laat hulle toe om 'n projekforum te stig vir onderhandeling met die projekpromotor oor daardie aspekte wat hulle glo hulle sal beïnvloed.

3. Vestig 'n gereelde kommunikasie- en inligtingsprogram (-sentrum) gekoppel aan 'n werkskomitee wat dien as skakel tussen die publiek (deur die projekforum) en die bestuur van die projek. Skep dus 'n klimaat van samewerking en deelname deur 'n wedersydse behoefte aan deelname en inligting te bevestig.

4. Om 'n projek moontlik te maak moet die 'kliënt vir die projek' en die 'kliënt vir die produk' konsensus bereik. Die projekforum kan hiervoor aangewend word, wat aanleiding gee tot 'n organisasiestruktuur soos getoon in Bylae D.

Daar is reeds aangetoon dat die projekspan nie 'n voorafbepaalde projekkonsep na die gemeenskap kan bring nie, maar 'n proses van projekkonsepvorming saam met die (georganiseerde) gemeenskap moet deurloop, soos in (1) tot (3) hierbo uiteengesit en geillustreer in Bylae C. Hierdie fase kan as 'n voorloper tot die konvensionele projeklewensiklus beskou word, is nie serieel nie en kan tewens verskeie siklusse benodig voordat voldoende konsensus met en in die gemeenskap bereik word.

\section{Samovatting}

Die meeste ingenieurs en projekbestuurders bestee weens hulle opleiding slegs geringe, indien enige, aandag aan die faktore en dinamika van die sosiale omgewing waarin hulle projekte moet beplan en uitvoer. Die kontemporêre situasie in Suid-Afrika, en wat waarskynlik nie in die afsienbare toekoms sal verander nie, is egter dat 'n projek eintlik net 'n element word van die sosiale stelsel heersend in die betrokke omgewing. Dit beteken dat die sosiale dinamika wat binne so 'n stelsel ontstaan nou primêre aandag moet kry en 'n belangrike suksesfaktor geword het by die implementering van enige projek wat die potensiaal het om 'n gemeenskap te beïnvloed.

Die tipiese opleiding van projekbestuurders en ingenieurs in hierdie 'sagte' stelsels van projekbestuur is klaarblyklik nie voldoende nie en behoort dringend aangespreek te word. 'n Studie van die basiese menseregte, die rol van arbeidsverhoudinge en die vakunies, onderhandelingsvaardighede, mikrobeplanningstegnieke, fasiliteringsvaardighede en -prosedures en ' $n$ begrip van die verskillende basiese kulturele etieke in Suid-Afrika is sommige van die prominentste vaardighede wat aandag behoort te geniet. Aansienlike bewyse uit etlike mislukte projekte in beide die openbare en privaatsektore wat op die 'konvensionele' manier aangepak is, bevestig 
dat die meeste, indien nie alle, projekte eenvoudig nie sal slaag nie tensy daar omvattende konsultasie met die publiek plaasvind vanaf die vroegste moontlike stadium.

\section{Verwysings}

Bamberger, M. 1988. The role of community participation in development planning and project management, EDI policy seminar report no 13. Washington, DC.: The World Bank. 36p.

Brown, C. 1994. The determinants of successful project management in local governments appropriate for the new South Africa. Referaat aangebied by die 25th PMI (1994) Symposium/Seminar, 17 19 October 1994, Vancouver, Kanada.

Chambers, R. 1993. Challenging the professions. Londen: Intermediate Technology Publications Ltd. 143p.

CUTA - Committee of Urban Transport Authorities. 1990. UTG11. Public participation in land use/transport planning. Pretoria: Department of Transport. 104p.

Goethert, R \& Hamdi, N. 1988. Making microplans. Londen: Intermediate Technology Publications Ltd. 79p.
Mokgoro, J. 1993. Community participation in project management. Ongepubliseerde lesing aan studente van die Opleidingsentrum vir Plaaslike Owerheidsaangeleenthede. Maart, Bellville.

Paul, S. 1987. Community participation in development projects. The World Bank experience. Washington, DC.: The World Bank. $37 \mathrm{p}$.

Stewart, G. 1993. 'Squatter areas upgraded in landmark project', $S A$ Construction World', August: 22-26.

Siviele Ingenieurswese in SA. 'Local community benefits from holistic approach to project', Vol 1, 10, Oktober: 8-9.

\section{Aantekening}

1. PMBOK staan vir 'Project Management Body of Knowledge' wat deur die Project Management Institute (130 South State Road, Upper Darby, Pennsylvania 19082, VSA) aan sy lede wêreldwyd as dié noodsaaklike kennis- en studiemateriaal voorgehou word.

\section{Bylae A Sosiale stelselbenadering}

Tegniese parameters

- bestuur van die projek

- professionele insette

Regeringsbelange (H.O.P.) - kliënt vir die projek
Oorhoofse politieke magstryd

- relevansie van politieke groeperinge

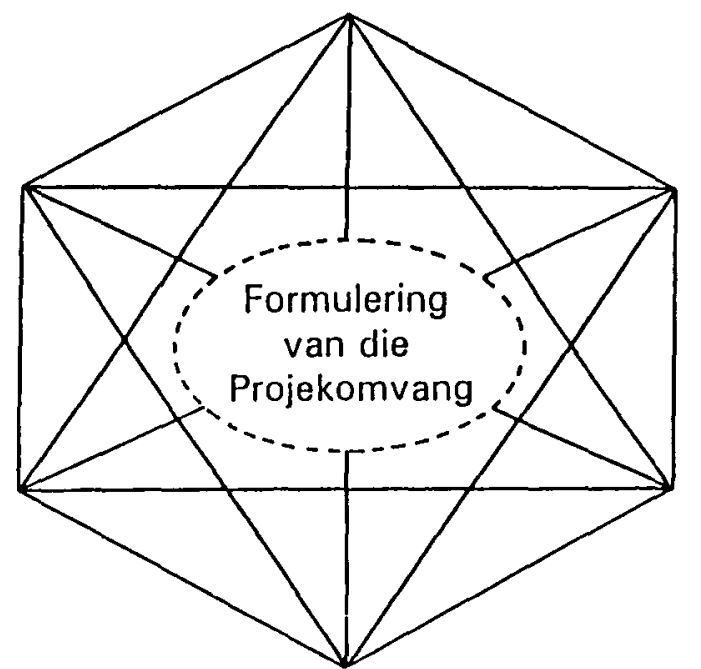

Plaaslike magstryd - plaaslike leier se beheer - beheer van toegang tot die gemeenskap

Emosies wat deur die projek ontketen word
Gemeenskapsbelange

- kliënte vir die produk

- verwagtinge

- buitengewone rol van mense met vaardighede 
Bylao B Oorgang van projekformulering na projekbestuur

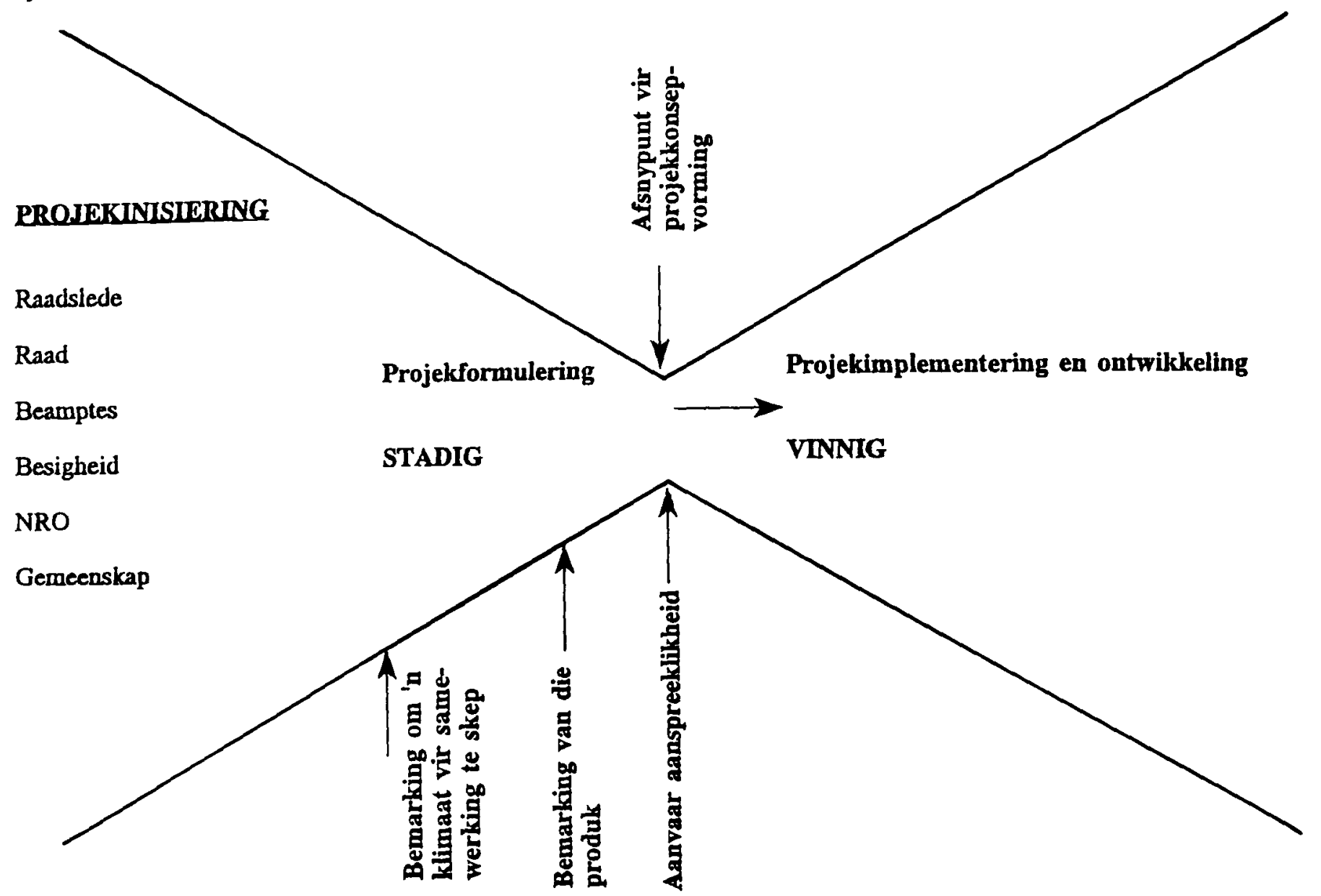

Bylae C Proses vir projekkonsepvorming

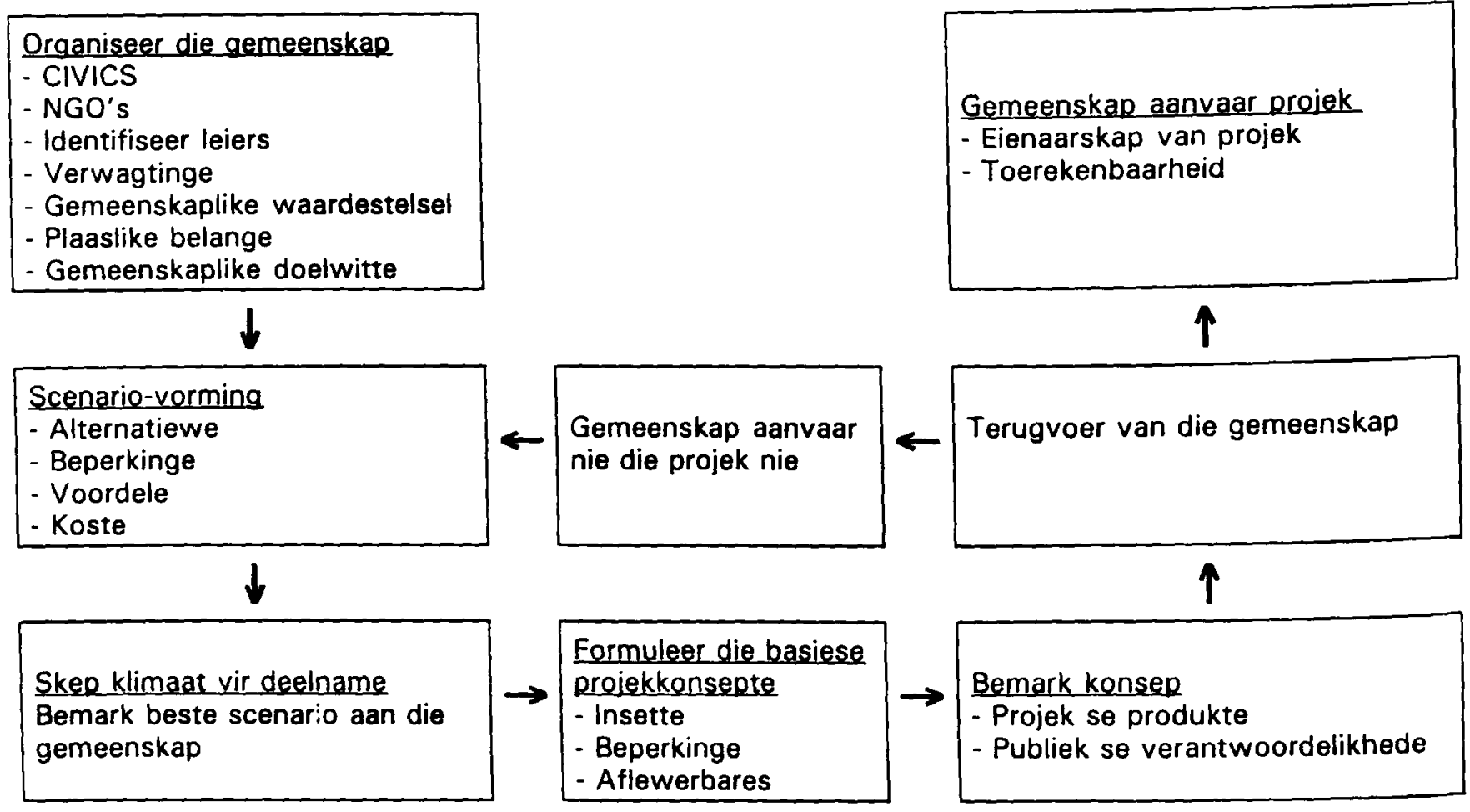




\section{Byla D Projekorganisasiestruktuur}

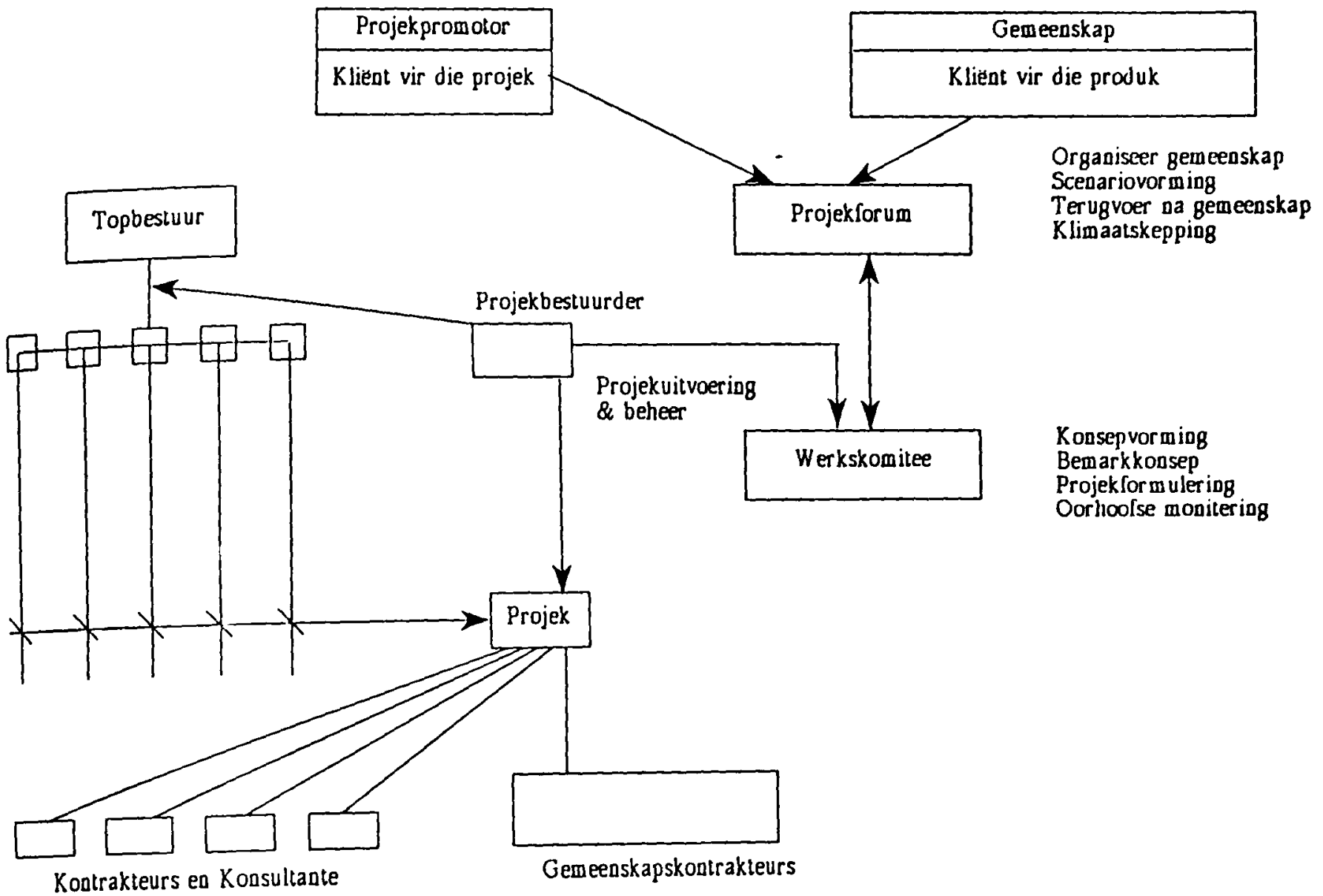


several separate issues. In all 73 initiatives were mentioned. Of these 27 had been completed, 45 were still in progress and one had been suspended.

Out of these 73 initiatives, 19 distinct activities were described. These were grouped into the following five categories:

- changing communications

- new systems

- reorganising IS

- changing technical architecture

- strategic planning

In Table 4 the categories in descending order by number occurrences are listed, and within each category by the number of respondents citing an individual activity. Brief descriptions of the initiative categories are provided below.

The changing communications category includes initiatives dedicated to building a communications infrastructure in both hardware and software. These initiatives involved both intraand inter-organizational communications and systems, and comprised by far the largest category of initiatives. They were, however, generally not regarded as the most important of the initiatives and were in many cases cited as a means of supporting other systems and management initiatives.

The new systems category included all systems development or acquisition initiatives. The systems development efforts ranged from a complete redevelopment of the Transaction Processing Systems to an ongoing effort to extend the functionality of the existing system. Two systems involved the introduction of new technology (scanning) while the largest number of initiatives cited in this category was in respect of a switch to package systems. Several computerization of manual system initiatives were also cited, showing that managers are still very much involved in traditional systems development issues (see Table 4).

The reorganising IS category reflects changes in the staffing of the IS functions, as well as changes to internal IS processes and responsibilities. Within the category the most prominent initiative was that of shifting the responsibility for and/or the ownership of the systems to the users, which in one case involved physically distributing IS staff to user sites and responsibility. Rightsizing in respect of the number of staff was also important, and although this was the term used, it generally meant 'downsizing'. Interestingly, outsourcing was cited by only one respondent, as was the reorganizing of staff into task-oriented, self-managed teams.

The changing technical architecture category reflects the effort to build an integrated technology infrastructure. The dominant activities in this category included a switch to client-server technology, and efforts to improve the integration of applications and reduce duplicated efforts. The switch to client-server was in several cases already accomplished, and in all cases where it was cited, the company had committed to making client-server the IT architecture of the future. The move to client-server was the most important initiative in four out of five cases.

In the context of this study, the strategic planning category reflects specific efforts to plan for and identify IS priorities. As many as 33 out of the 73 initiatives mentioned were said to be the result of strategic information systems planning (SISP), as shown in Table 5. A SISP is a deliberate interven-
Table 4 IT initiatives by number of occurrences

\begin{tabular}{|c|c|}
\hline Initiative & Total \\
\hline Changing communications & 26 \\
\hline LAN/WAN development & 15 \\
\hline Edi & 7 \\
\hline e-mail system & 4 \\
\hline New systems & 16 \\
\hline Package systems & 5 \\
\hline Computerization of manual systems & 4 \\
\hline Rewrite TPS & 2 \\
\hline MIS & 2 \\
\hline Scanning & 2 \\
\hline Extend functionality of existing system & 1 \\
\hline Reorganizing IS & 13 \\
\hline Shifting responsibility/ownership to users & 5 \\
\hline 'Rightsizing' & 4 \\
\hline $\begin{array}{l}\text { Consolidation of distributed functions/ } \\
\text { depts }\end{array}$ & 2 \\
\hline Restructuring dept into task-oriented teams & 1 \\
\hline Outsourcing & 1 \\
\hline Changing tech architecture & 12 \\
\hline Integration of existing systems & 5 \\
\hline Change to client-server technology & 5 \\
\hline RDBMS & 2 \\
\hline Strategic planning & 6 \\
\hline Alignment with corporate strategy & 4 \\
\hline Evaluation of IT spending & 2 \\
\hline Total & 73 \\
\hline
\end{tabular}

tion in the process of the establishment of a firm's IS requirements, to attempt to utilize IS to deliver a strategic or competitive advantage. However, there were five initiatives which were themselves planning activities. Three respondents cited initiatives specifically aimed at aligning IT with corporate strategy. This together with the fact that 44 of the 73 initiatives were either the result of SISP or initiated to some degree by users, indicates that there is substantial senior management commitment and functional manager participation in the IT planning process. One respondent cited two separate budgeting activities which were aimed at establishing the value of the IT infrastructure to the organization. None of the respondents cited Business Process Re-engineering (BPR) as an initiative, but three did mention that there were plans for a BPR project in the organization, and that the initiatives being undertaken by IS were seen as enablers of that project (see Table 5).

The initiatives described lead us to the following conclusions about changes in IS management:

- There is a strong move toward changing technical architectures and establishing communication systems which will spread IS throughout the organization.

- Many South African managers are still concerned with establishing TPS and MIS systems. 
Table 5 Was the initiative identified as a result of SISP?

\begin{tabular}{llc}
\hline YES & \multicolumn{1}{c}{ NO - instigated by: } \\
\hline & finance & 3 \\
& marketing & 2 \\
& operations & 1 \\
& management & 1 \\
& users generally & 1 \\
& total users & 8 \\
& users + IT & 3 \\
& IT & 22 \\
& no planning - 'a necessiry' & 7 \\
\hline 33 & & 40 \\
\hline
\end{tabular}

- There is a strong move towards shifting responsibility and ownership of the systems to the users. In addition IS departments are generally not growing or are even shrinking in size. Only 12 of the initiatives required the acquisition of new staff, while 51 did not and 10 resulted in a decrease in the number of staff.

- There is increasing participation by high-level business managers in the planning process, and a corresponding awareness amongst IT managers of the need to align IT with business strategy.

\section{Findings on drivers}

A total of six drivers for the initiatives were identified:

- business value

- partnership with users

- IS department productivity

- an external directive

- IT trends

- staff effectiveness

Many executives had more that one driver for each initiative. There were on average, 1.3 drivers for each initiative. Table 6 provides a summary of the number of times a driver was mentioned and the number of respondents who identified that driver.

Business value refers to attempts to use IS to contribute to the bottom line of the organization as a whole. Initiatives were said to be in this category when IS executives said that they wanted to provide a business solution, comprehensive business coverage, cost savings to the company, better information for business needs, improved customer service, increased revenue, efficiency in process or increased market share. In general this category relates to IS executives concern with contributing to the competitiveness of the organization.

Table 6 Drivers for initiatives

\begin{tabular}{lcccccc}
\hline & \multicolumn{2}{c}{$\begin{array}{c}\text { Business Partner- } \\
\text { value }\end{array}$} & $\begin{array}{c}\text { IT dept } \\
\text { shivers }\end{array}$ & $\begin{array}{c}\text { External } \\
\text { productivity directive }\end{array}$ & $\begin{array}{c}\text { IT } \\
\text { trends effectiveness }\end{array}$ \\
$\begin{array}{l}\text { \# of times } \\
\text { mentioned }\end{array}$ & 50 & 8 & 13 & 4 & 13 & 6 \\
$\begin{array}{l}\text { \# of respond- } \\
\text { ents mentioning }\end{array}$ & 21 & 4 & 7 & 3 & 7 & 4 \\
\hline
\end{tabular}

Business value was cited as a driver in $68 \%$ of the initiatives. Every type of management initiative was considered to have an impact on business value by one or more respondents. However, the initiatives which were most often seen as contributing to Business Value were the development of new systems, the establishment of communication systems and the reorganising of the ISD.

Partnership was used as a driver where executives expressed a desire to improve the relationship between IS and user management. Drivers which were placed in this category included a need for greater user satisfaction, increased user involvement and awareness, or a need for communication. Partnership was mentioned only eight times as a driver, and significantly in respect of shifting responsibility or ownership for IS to users.

The IT Department Productivity driver reflects a need to reduce the cost of building, operating and maintaining systems. This can be done either by increasing the outputs using the same inputs, or using less inputs to achieve the same outputs. Generally the respondents spoke of attempts to reduce the required inputs. Drivers in this category include increasing efficiency of working on systems, improvement of internal systems, increasing productivity and coping with overloading of IS staff. Altogether 13 initiatives were undertaken for this reason, most notably the consolidation of distributed functions, the development of networks, rightsizing of the ISD and the integration of existing systems.

Initiatives were classified as being driven by an external directive if they were undertaken on instructions from outside the organization in South Africa. Four initiatives were undertaken on this basis, two on instruction from international parent companies and two on instruction from the owners of the organization.

IT trends was used as a driver classification where respondents said that they undertook initiatives because of pressure from users to have current technology, a need to keep pace with external IT trends or because everyone else in the industry is moving towards the technology. Altogether 13 initiatives were undertaken for this reason, most of them in the areas of technical architecture changes and telecommunications developments.

Staff effectiveness is a driver relating to the effective use of non-IS staff. Comments which caused a driver to be placed in this category include labour saving, making effective use of staff, providing service to staff and improving the internal functioning of the organization. This was important in only six of the initiatives, and mostly in changing communications - providing networks and e-mail facilities.

\section{Findings on benefits}

Respondents were asked what kinds of benefits they anticipated from the initiatives in terms of automation, management information or transformation. A definition of these terms is given in Table 7. The responses are summarized in Appendix $C$. In the case of six of the initiatives, the respondents felt that the benefits would not fall into any of these categories. Of the remaining initiatives, many were felt to provide more than one type of benefit. On average, there were two types of benefit cited for each initiative. Respondents felt in some cases that a benefit could transform, or 
inform without also automating. Where this was felt, the initiatives were usually not directly systems related, that is they were strategic planning or reorganizing IS initiatives.

Most of the changing technical architectures, communications systems and new systems were expected to provide automation benefits. In some cases this meant the automation of previously manual tasks, such as transferring data, while in others it meant the improved automation of existing computerized tasks. Many of the reorganizing IS initiatives were also expected to provide automation, in the sense that command and control would be improved.

The results suggest that $73 \%$ of the initiatives were expected to provide information benefits, as defined in Table 7. All the strategic planning initiatives, and most of the reorganizing IS and changing architecture and communications initiatives were done for this purpose. The same number of new systems which were expected to provide automation, were also expected to provide information.

Automation and information benefits were mostly what the initiatives were aimed at achieving. Only 28 initiatives (38\%) were expected to provide transformation, and most of these were in the area of changing communications. New systems which computerized manual systems, or introduced new technology such as scanning, were also expected to change the way in which the organization did business.

The decreasing emphasis on measurement found in the literature is reflected in this study by the number of initiatives where benefits were not quantified either ex-ante $-62 \%$, or ex-post $-50 \%$. Where benefits were said to be quantified in advance $32 \%$ of the measures could not be specified. Respondents just seemed to be sure that they had done some sort of quantification. Benefits which were quantified ex-post were quantified in terms of cost savings in $48 \%$ of the cases and using non-financial measures in $35 \%$ of the cases.

\section{Discussion of results}

Of the six issues which were identified by Ross et al. (1994) as growing concerns of IS executives (see the second section), only three were addressed in initiatives undertaken by the respondents. These are:

- aligning IT with strategic goals;

- building technology infrastructures; and

- developing or managing IS human resources.

Of these, building technology infrastructures was of most concern to the companies interviewed. This is being done through the integration of existing systems, a move to clientserver and the development of telecommunications infrastructures. Ross et al. (1994) suggest that this might signal a shift from a portfolio or list of applications mentality to an infrastructure mentality. The multiple platforms and shared databases which will comprise this infrastructure will re-

Table 7 Types of benefits

\begin{tabular}{ll}
\hline automation: & reinforcing command and control \\
information: & enabling work to be done more flexibly \\
transformation: & changing the way work is done \\
(Zuboff, 1988) & \\
\hline
\end{tabular}

quired strict standards and control on the part of IS management.

Aligning IT with organizational strategy is less important to South African managers, although those who did mention it stressed its significance. This is being done primarily for the business value to be gained, and only one respondent spoke of the partnership between users and IS which this would require. It should, however, be mentioned again that a majority of the initiatives undertaken were instigated with some degree of user participation, which indicates that a measure of partnership exists already.

The management of IS human resources is being done primarily through moving IS people within the organization, or alternatively, out of the organization. Development of human resources seems to happen as a consequence of other initiatives, rather than as a particular effort in itself. Staff training was undertaken in 53 of the 73 initiatives.

The issue of improving the software development does not appear to have been formally addressed as an initiative in itself, although a substantial portion of the initiatives undertaken were themselves software development projects. The noticeable move to package systems, however, may be seen as an attempt to address problems of software development in the organizations concerned. As discussed above, the issue of Business Process Re-engineering does not appear to be of direct concern to South African IS managers at this stage, and the issue of managing data as a resource was not mentioned once.

The importance of communications technology in the form of LANs and EDI as perceived by South African managers in the Delphi Study conducted by Remenyi \& Sutherland (1993) is supported by the results of this study which show that initiatives are being undertaken using these technologies. Remenyi \& Sutherland suggest that the importance of LANs is growing because of increasing emphasis on reconfiguring the firm within a context of enterprise networking. Moving beyond the boundaries of a single organization, a similar reconfiguring of industry is taking place through enterprise to enterprise networking in the form of EDI. These changes are brought about by the transformation which these initiatives in particular have been said to provide.

The findings are largely consistent with prior literature, but they do suggest that some issues have not yet become of major concern to South African IS managers. There seems to be great concentration on physical aspects of providing systems: building architectures, telecommunications and transaction systems. Considerations which are not strictly technology related, such as strategic planning, organizational structure and Business Process Re-engineering are receiving less attention.

\section{Conclusion}

In comparing our results for South Africa with those of Ross et al., South African IS management appears to be keeping pace with world trends, and even moving ahead in some instances. Ross et al. (1994) found that American executives were developing initial plans for a move to client-server, while many South African respondents were already engaged in this move. There was also a strong move towards establishing intra- and inter-organizational communications systems. 
However, South African managers seem to be less concerned with the soft managerial issues of Information Management than their US counterparts. Ross et al. noted that their respondents were addressing multiple objectives through multiple initiatives, and that these frequently included issues of alignment, organization and staff development. Business Process Re-engineering was also a top priority of many US executives, while this was not the case amongst the respondents in South Africa.

The ultimate objective of IS managers appears, in both this study and the study conducted by Ross et al. (1994) to be creating business value. However, managers need to convince business partners that IT investments can create business value, thereby developing effective partnerships and ultimately obtaining funding for further initiatives. While many South African managers are partnered with business managers in developing initiatives, there perhaps needs to be a more explicit attempt to build partnership and make it clear to upper management that IT investment can be used to create business value.

\section{Keywords}

IS Management, IS Evaluation, IS Management Issues.

\section{Acknowledgements}

The study described in this article was inspired by the work of Jeanne Ross, Cynthia Beath and Dale Goodhue who presented a report on research in progress entitled $\mathbf{R e}$ inventing the IS Organisation: new practices for managing Information Technology, at ICIS 1993 in Orlando, Florida. Ms. Ross, a research associate at the Center for Information Systems Research at MIT, also sent us a copy of the working paper describing the final results, when we requested further information on the study. This working paper proved to be very useful in understanding the method of research, which was very similar to that which we employed, and the differences and similarities between United States and South African experiences in the management of IS resources.

We owe thanks to the following post-graduate students in the Department of Information Systems who assisted in data collection: Dimitra Bamboulis, Lee-Anne Denham, Alison Heafield, Adele Margow, Veliswa Msizi, Kevin Rothschild, George Vircik.

\section{Note}

1. Although some authors attempt to attribute different meanings to the expressions Information Systems and Information Technology, in this article, we have deliberately used these terms interchangeably.

\section{References}

Branchau, J.C. \& Wetherbe, J.C. 1987. 'Key issues in information systems management', MIS Quarterly, Vol. 11, No. 1.

Cash, J.I., McFarlan, F.W., McKenney, J.L. \& Applegate, L.M. 1992. Corporate information systems management, text and cases, $3 \mathrm{rd}$ ed. Homewood: Irwin.

Champy, J.A. 1993. 'Grand designs', CIO, January.

Davenport, T.H. 1993. Process innovation: reengineering work through information technology. Boston: Harvard Business School Press.

Earl, M.J. 1990. Approaches to strategic information systems planning experience in twenty-one United Kingdom companies, Proceedings of the 11th International Conference on Information Systems.

Haekel, S.H. \& Nolan, R.L. 1993. 'Managing by wire', Harvard Busi- ness Review, Vol. 71, No 5.

Hammer, M. 1990. 'Re-engineering work: don't automate, obliterate'. Harvard Business Review, Vol. 68, No. 4.

Herbert, M. \& Hartog, C. 1986. '1985 opinion survey of MIS managers: key issues', MIS Quanerly, Vol. 9 No. 4.

Hopper, M.D. 1990. 'Rattling SABRE - new way to compete on information', Harvard Business Review, Vol. 68, No. 3.

Huber, R.L. 1993. 'How Continental bank outsourced its crown jewels', Harvard Business Review, Vol. 71, No. 1.

Remenyi, D. 1991. Introducing strategic information systems planning. Manchester: NCC Blackwells.

Remenyi, D. 1993. Information management case studies. London: Pitmans Publishing.

Remenyi, D.S.J. \& Sutherland, F. 1993. 'Key information technologies in the mid-1990s as perceived by the accounting profession and business managers', De Ratione, Vol. 7, No. 1.

Rockart, J.F. 1988. 'The line takes the leadership - IS management in a wired world, Sloan Management Review, Vol. 29 No 4.

Ross, J.W., Beath, C.M. \& Goodhue, D.L. 1994. Reinventing the IS organisation: evolution and revolution in IT Management practices. Working paper.

Synnott, W. 1987. The information weapon. New York: John Wiley and Sons.

Wiseman, C. 1985. Strategy and computers - information systems as a competitve weapon. Boston: Dow-Jones Irwin.

Zuboff, S. 1988. In the age of the smart machine. London: Heinemann.

Appendix A Major IT initiatives - content analysis

\begin{tabular}{|c|c|c|c|c|c|}
\hline Initiative & Ranked & lanked 2 & Ranked 3 & Not ranked & Total \\
\hline Changing communications & 5 & 12 & 5 & 4 & 26 \\
\hline LAN/WAN development & 4 & 7 & 1 & 3 & 15 \\
\hline Edi & - & 3 & 4 & - & 7 \\
\hline e-mail system & 1 & 2 & - & 1 & 4 \\
\hline New systems & 7 & 1 & 4 & 4 & 16 \\
\hline Package systems & 2 & - & 1 & 2 & 5 \\
\hline $\begin{array}{l}\text { Computerization of manual } \\
\text { systems }\end{array}$ & 2 & - & - & 2 & 4 \\
\hline Rewrite TPS & 1 & 1 & - & - & 2 \\
\hline MIS & - & - & 2 & - & 2 \\
\hline Scanning & 2 & - & - & - & 2 \\
\hline $\begin{array}{l}\text { Extend functionality of } \\
\text { existing system }\end{array}$ & - & - & 1 & - & 1 \\
\hline Reorganizing IS & 2 & 2 & 5 & 4 & 13 \\
\hline $\begin{array}{l}\text { Shifting responsibility/ } \\
\text { ownership to users }\end{array}$ & - & 1 & 2 & 2 & 5 \\
\hline 'Rightsizing' & - & - & 2 & 2 & 4 \\
\hline $\begin{array}{l}\text { Consolidation of distributed } \\
\text { functions }\end{array}$ & - & 1 & 1 & - & 2 \\
\hline $\begin{array}{l}\text { Restructuring depth into } \\
\text { task-orientated teams }\end{array}$ & 1 & - & - & - & 1 \\
\hline Outscoring & 1 & - & - & - & 1 \\
\hline Changing tech argitecture & 5 & 3 & 2 & 2 & 12 \\
\hline $\begin{array}{l}\text { Integration of existing } \\
\text { systems }\end{array}$ & - & 1 & 2 & 2 & 5 \\
\hline $\begin{array}{l}\text { Change to client-server } \\
\text { technology }\end{array}$ & 4 & 1 & - & - & 5 \\
\hline RDBMS & 1 & 1 & - & - & 2 \\
\hline Strategic planning & 1 & 4 & 0 & 1 & 6 \\
\hline $\begin{array}{l}\text { Alignment with corporate } \\
\text { strategy }\end{array}$ & 1 & 2 & - & 1 & 4 \\
\hline Evaluation of IT spending & - & 2 & - & - & 2 \\
\hline Total & 20 & 22 & 16 & 15 & 73 \\
\hline
\end{tabular}


Appendix B Major IT initiatives - correspondence analysis, initiatives versus drivers

\begin{tabular}{|c|c|c|c|c|c|c|c|c|}
\hline \multirow[b]{2}{*}{ Initiative } & \multicolumn{5}{|c|}{ IT dept } & \multirow{2}{*}{$\begin{array}{c}\text { Staff } \\
\text { effect- } \\
\text { iveness }\end{array}$} & \multirow{2}{*}{$\begin{array}{c}\text { Total } \\
\text { driver } \\
s\end{array}$} & \multirow{2}{*}{$\begin{array}{l}\text { Total \# of } \\
\text { initiatives }\end{array}$} \\
\hline & $\begin{array}{l}\text { Business } \\
\text { value }\end{array}$ & $\begin{array}{l}\text { artner- } \\
\text { ship }\end{array}$ & ductiv & $\begin{array}{l}\text { External } \\
\text { directive tr }\end{array}$ & $\begin{array}{l}\text { IT } \\
\text { rends }\end{array}$ & & & \\
\hline Changing communications & 18 & 2 & 4 & 1 & 5 & 4 & 34 & 26 \\
\hline LAN/WAN development & 12 & 1 & 4 & - & 2 & 2 & 21 & 15 \\
\hline Edi & 5 & - & - & - & 3 & - & 8 & 7 \\
\hline e-mail system & 1 & 1 & - & 1 & - & 2 & 5 & 4 \\
\hline New systems & 12 & 2 & 0 & 3 & 2 & 1 & 20 & 16 \\
\hline Package systems & 3 & - & - & 2 & 1 & - & 6 & 5 \\
\hline $\begin{array}{l}\text { Computerizaion of manual } \\
\text { systems }\end{array}$ & 3 & - & - & - & - & 1 & 4 & 4 \\
\hline Rewrite TPS & 1 & 1 & - & - & 2 & & & \\
\hline MIS & 1 & 1 & - & 1 & - & - & 3 & 2 \\
\hline Scanning & 2 & - & - & - & 1 & - & 3 & 2 \\
\hline $\begin{array}{l}\text { Extend functionality of existing } \\
\text { systems }\end{array}$ & 1 & - & - & - & - & - & 1 & 1 \\
\hline Reorganizing IS & 9 & 2 & 5 & 0 & 1 & 1 & 18 & 13 \\
\hline $\begin{array}{l}\text { Shifting respons./ownership to } \\
\text { users }\end{array}$ & 1 & 2 & 1 & - & - & 1 & 5 & 5 \\
\hline 'Rightsizing' & 4 & - & 2 & - & - & - & 6 & 4 \\
\hline $\begin{array}{l}\text { Consolidation of distributed } \\
\text { functions }\end{array}$ & 2 & - & 2 & - & - & - & 4 & 2 \\
\hline $\begin{array}{l}\text { Restructuring depth into task- } \\
\text { orientated teams }\end{array}$ & 1 & - & - & - & - & - & 1 & 1 \\
\hline Outscoring & 1 & - & - & - & 1 & - & 2 & 1 \\
\hline Changing tech argitect & 7 & 1 & 4 & 0 & 5 & 0 & 17 & 12 \\
\hline Integration existing systems & 3 & - & 2 & - & 1 & - & 6 & 5 \\
\hline $\begin{array}{l}\text { Change to client-server } \\
\text { technology }\end{array}$ & 2 & 1 & 1 & - & 3 & - & 7 & 5 \\
\hline RDBMS & 2 & - & 1 & - & 1 & - & 4 & 2 \\
\hline Strategic planning & 4 & 1 & 0 & 0 & 0 & 0 & 5 & 6 \\
\hline Alignment with corporate strategy & 3 & 1 & - & - & - & - & 4 & 4 \\
\hline Evaluation of IT spending & 1 & - & - & - & - & - & 1 & 2 \\
\hline Total & 50 & 8 & 13 & 4 & 13 & 6 & 94 & 73 \\
\hline
\end{tabular}


Appendix C Major IT initiatives - correspondence analysis, initiatives versus benefits

\begin{tabular}{lcccccc}
\hline Initiative & $\begin{array}{c}\text { Auto- } \\
\text { mation }\end{array}$ & $\begin{array}{c}\text { Inform- } \\
\text { ation }\end{array}$ & $\begin{array}{c}\text { Trans- } \\
\text { formation }\end{array}$ & $\begin{array}{c}\text { Total } \\
\text { benefits }\end{array}$ & $\begin{array}{c}\text { Not } \\
\text { specified }\end{array}$ & $\begin{array}{c}\text { Total of } \\
\text { initiatives }\end{array}$ \\
\hline Changing communications & 23 & 19 & 11 & 53 & 0 & 26 \\
LAN/WAN development & 13 & 11 & 5 & 29 & - & 15 \\
Edi & 6 & 5 & 4 & 15 & - & 7 \\
e-mail system & 4 & 3 & 2 & 9 & - & 4 \\
\hline New systems & 12 & 12 & 7 & 31 & 1 & 16 \\
Package systems & 4 & 4 & 2 & 10 & - & 5 \\
Computerization of manual & & & & & & \\
systems & 3 & 3 & 2 & 8 & - & 4 \\
Rewrite TPS & 1 & 1 & - & 2 & & 2 \\
MIS & 2 & 2 & 1 & 5 & - & 2 \\
Scanning & 1 & 1 & 1 & 3 & 1 & 2 \\
$\begin{array}{l}\text { Extend functionality of } \\
\text { existing system }\end{array}$ & 1 & 1 & 1 & 3 & - & 1 \\
\hline $\begin{array}{l}\text { Reorganizing IS } \\
\text { Shifting respons./ownership to }\end{array}$ & 8 & 9 & 4 & 21 & 1 & 13 \\
users & 3 & 4 & 1 & 8 & - & 5 \\
'Rightsizing' & 3 & 2 & 2 & 7 & - & 4 \\
$\begin{array}{l}\text { Consolidation of distributed } \\
\text { functions }\end{array}$ & 1 & 2 & - & 3 & - & 2 \\
Restructuring depth into task- \\
orientated teams
\end{tabular}

